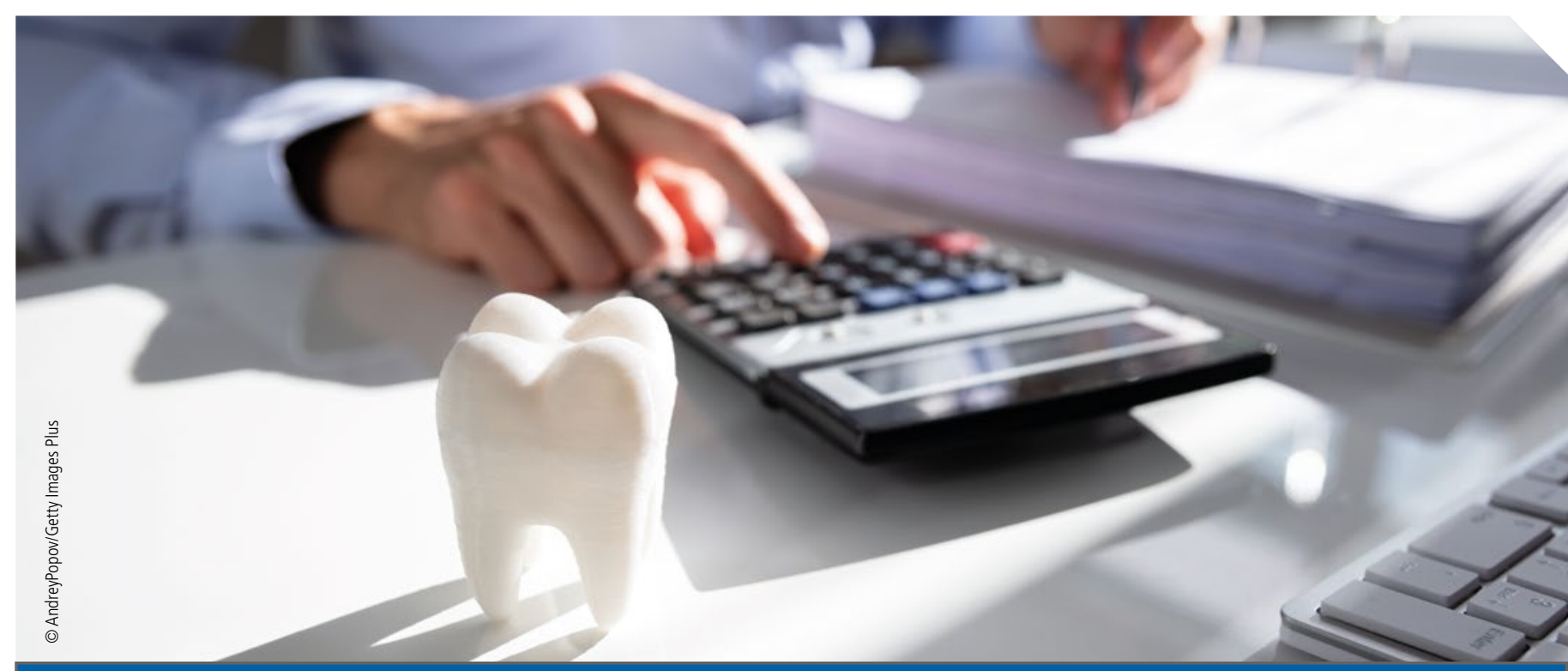

\title{
Clarification on SEISS
}

The National Association of Specialist Dental Accountants and Lawyers (NASDAL) have welcomed clarification on the potential issues that may arise when dentists were eligible to claim the Self-Employment Income Support Scheme (SEISS) grant whilst also receiving their usual level of NHS income. It was highlighted that the amount of grant received may exceed the reduction of private income.

The eligibility criteria for the SEISS grant requires that you have been adversely affected by COVID-19 and that your average selfemployed earnings (from all sources) over the last three tax years have not exceeded
$£ 50 \mathrm{k}$ pa. HMRC have confirmed that if part of a dental practitioners' income (private income) reduces, but another part remains the same (NHS income), it is legitimate for a claim to be made in full and retained.

Alan Suggett, specialist dental accountant partner in UNW LLP and NASDAL

Media Officer said: 'We have received communication from the BDA following discussions with NHS England on this matter and they confirmed that receiving both NHS income and the SEISS grant does not constitute a duplication of wider government support and therefore does not breach any of the terms of the NHS contract payment arrangements.'

Fellow NASDAL accountant Johnny Minford of Minford \& Co, who has a number of clients in Northern Ireland added: 'However, our Principal colleagues in Northern Ireland still have a problem as the mechanism there does not permit a double claim and the choice is in the hands of associates. There could be practices where the associate has chosen to claim SEISS, so the practice gets NONE of the IOS payment due for the associates' proportion of the healthcare.'

\section{FGDP(UK) announces Vice Deans}

Susan Nelson and Onkar Dhanoya have been inaugurated as the new Vice Deans of the Faculty of General Dental Practice (FGDP(UK))

Susan was elected to represent the region on the Faculty Board in 2017, re-elected earlier this year and chairs the FGDP(UK) Education and Qualifications Committee. She is also Deputy Chair of the Northern Ireland branch of the BDA and will take on the role of Regional Clinical Lead for Portman Healthcare later this year.

Graduating from Newcastle University in 1985, Onkar represents the Yorkshire and Northern region on the FGDP(UK) Board and holds Fellowships both of the FGDP(UK) and the International College of
Dentists. He chairs the Faculty's Professional Affairs Committee and served as Vice-Dean from 2018-19.

The new Vice Deans were elected by the Board for one-year terms, and succeed Abhi Pal and Roshni Karia.

Ian Mills, Dean of FGDP(UK),
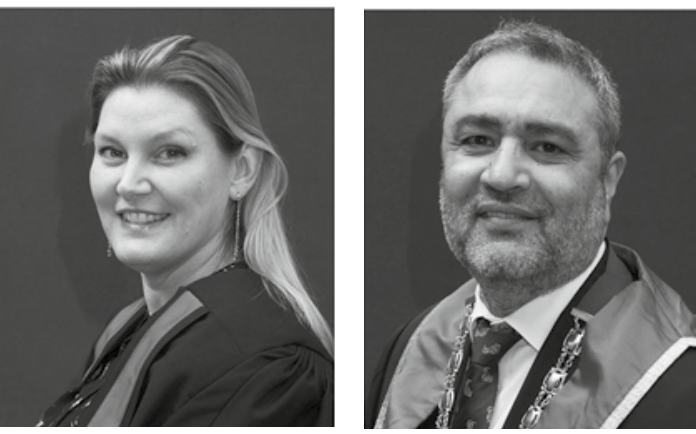
commented: 'On behalf of all members of the Faculty, I congratulate Susan and Onkar on their election as ViceDeans. They bring with them significant experience and insight into general dental practice, which will be of great benefit to myself, FGDP and the wider profession in their new roles. I would also like to express my thanks and appreciation to Abhi and Roshni for their advice and hard work over the last twelve months, and in particular for their support throughout the current pandemic, and I am delighted that they will continue to play important roles on the Board.' 